\section{(6) OPEN ACCESS}

\title{
OCT for glaucoma diagnosis, screening and detection of glaucoma progression
}

\author{
Igor I Bussel, ${ }^{1}$ Gadi Wollstein, ${ }^{1}$ Joel S Schuman ${ }^{1,2}$
}

\begin{abstract}
${ }^{1}$ Department of Ophthalmology, UPMC Eye Center, Eye and Ear Institute, Ophthalmology and Visual

Science Research Center, University of Pittsburgh School of Medicine, Pittsburgh, Pennsylvania, USA

${ }^{2}$ Department of Bioengineering, Swanson School of Engineering, University of Pittsburgh, Pittsburgh, Pennsylvania, USA
\end{abstract}

\section{Correspondence to}

Dr Gadi Wollstein, Department of Ophthalmology, UPMC Eye Center, Eye and Ear Institute, 203 Lothrop Street, Pittsburgh, PA 15213;

wollsteing@upmc.edu

Received 13 September 2013 Revised 7 November 2013 Accepted 13 November 2013 Published Online First 19 December 2013

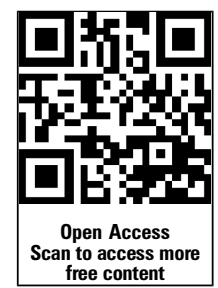

CrossMark

To cite: Bussel II, Wollstein G, Schuman JS. Br J Ophthalmol 2014;98: ii15-ii19.

\section{ABSTRACT}

Optical coherence tomography (OCT) is a commonly used imaging modality in the evaluation of glaucomatous damage. The commercially available spectral domain (SD)-OCT offers benefits in glaucoma assessment over the earlier generation of time domainOCT due to increased axial resolution, faster scanning speeds and has been reported to have improved reproducibility but similar diagnostic accuracy. The capabilities of SD-OCT are rapidly advancing with 3D imaging, reproducible registration, and advanced segmentation algorithms of macular and optic nerve head regions. A review of the evidence to date suggests that retinal nerve fibre layer remains the dominant parameter for glaucoma diagnosis and detection of progression while initial studies of macular and optic nerve head parameters have shown promising results. SD-OCT still currently lacks the diagnostic performance for glaucoma screening.

\section{INTRODUCTION}

Glaucoma is a multi-factorial optic neuropathy characterised by progressive structural loss of retinal ganglion cells (RGC) that may result in vision loss and irreversible blindness. The ability to detect structural loss is fundamental in the diagnosis and management of glaucoma. While glaucomatous structural damage can be assessed subjectively by clinically examining the optic nerve head $(\mathrm{ONH})$ and peripapillary retinal nerve fibre layer (RNFL), the introduction of ocular imaging modalities into clinical management has allowed for supplemental objective and quantitative evaluation of ocular structure.

Optical coherence tomography (OCT) is a commonly used imaging technology in the evaluation of glaucomatous structural damage. OCT was introduced over 20 years ago and is a non-invasive optical technique that allows for in vivo crosssectional imaging of the $\mathrm{ONH}$ and retina. ${ }^{1}{ }^{2}$ The recent commercially available iteration of the OCT technology, spectral domain (SD)-OCT, has theoretical advantages in glaucoma assessment over the earlier generation of time domain (TD)-OCT due to increased axial resolution and faster scanning speed that lead to lower susceptibility to eye movement artefacts. The evidence to date suggests that SD-OCT offers improved reproducibility; however, the glaucoma diagnostic accuracy of SD-OCT and TD-OCT is statistically similar. ${ }^{34}$

SD-OCT is rapidly evolving with faster scanning speeds, 3D image acquisition patterns, reproducible registration and advanced segmentation algorithms. The clinical utility of SD-OCT in glaucoma has primarily focused on the evaluation RNFL parameters because it enables a comprehensive assessment of all the RGC axons as they approach the $\mathrm{ONH}$. However, the variability of the surrounding structures and the presence of coexisting pathology may impact reliable measurement. As such, the enhanced performance of SD-OCT allows for the assessment of macular parameters for glaucoma evaluation because the macula has the highest concentration of RGC in the retina (approximately $50 \%$ of the RGC of the entire retina); thus, loss of these cells may potentially be more readily detected in this area. Furthermore, given the ability of $\mathrm{SD}-\mathrm{OCT}$ to produce $3 \mathrm{D}$ datasets, there is now potential to assess $\mathrm{ONH}$ parameters for glaucoma evaluation with greater accuracy and improved progression detection in consecutive testing by precise image registration. There are currently several commercially available SD-OCT devices with varying parameters and unique features. As such, the discussion of parameters and features provided in this manuscript may not be applicable across every SD-OCT device. In this manuscript, we review the recent advances in the use of SD-OCT for glaucoma diagnosis, screening and detection of progression.

\section{GLAUCOMA DIAGNOSIS}

The use of SD-OCT for glaucoma diagnosis has become a common clinical practice. Numerous studies have demonstrated that RNFL and macular thickness parameters are reproducible, and with high diagnostic sensitivity and specificity in discriminating between healthy and glaucomatous eyes (table 1$).^{45}$

The diagnostic capabilities of SD-OCT for discriminating between healthy and glaucomatous eyes using average RNFL thickness have been reported to have an area under receiver operating characteristics curve value of around 0.9. ${ }^{6}$ However, the discrimination ability is dependent on the severity stage of glaucoma, with better performance in discriminating between healthy and more advance disease compared with discrimination of early stages of glaucoma. ${ }^{7}$

Acquisition of 3D images of the $\mathrm{ONH}$ region enables accurate and reproducible measurements of $\mathrm{ONH}$ parameters that include: disc and rim area, cup to disc ratio, cup volume and others. A diagnostic capability study with SD-OCT of glaucoma and age-matched healthy controls reported that these $\mathrm{ONH}$ parameters are able to discriminate between healthy and glaucomatous eyes similar to RNFL thickness. ${ }^{8}$ Another study with glaucoma, preperimetric glaucoma and healthy subjects demonstrated that RNFL thickness was better than any tested $\mathrm{ONH}$ parameter. ${ }^{9}$ The contradictory 
Table 1 Summary of selected glaucoma diagnostic accuracy studies

\begin{tabular}{|c|c|c|c|c|c|c|c|}
\hline $\begin{array}{l}\text { Study, year } \\
\text { (reference) }\end{array}$ & Subjects & $\begin{array}{l}\text { Number of } \\
\text { eyes }\end{array}$ & $\begin{array}{l}\text { Baseline MD } \\
\text { (dB) }\end{array}$ & Device & $\begin{array}{l}\text { Scan } \\
\text { region }\end{array}$ & Parameter & AUC \\
\hline Mwanza $2011^{8}$ & $\begin{array}{l}\text { Glaucoma } \\
\text { Healthy }\end{array}$ & $\begin{array}{r}73 \\
146\end{array}$ & $\begin{array}{l}-10.4 \\
\mathrm{NA}\end{array}$ & Cirrus SD-OCT & $\begin{array}{l}\text { ONH } \\
\text { RNFL }\end{array}$ & $\begin{array}{l}\text { Vertical rim thickness } \\
\text { Rim area } \\
\text { RNFL average thickness }\end{array}$ & $\begin{array}{l}0.96 \\
0.96 \\
0.95\end{array}$ \\
\hline Sung $2012^{9}$ & $\begin{array}{l}\text { Glaucoma } \\
\text { Preperimetric } \\
\text { glaucoma } \\
\text { Healthy }\end{array}$ & $\begin{array}{l}229 \\
405 \\
109\end{array}$ & $\begin{array}{l}-6.64 \\
-0.66 \\
-0.45\end{array}$ & Cirrus SD-OCT & $\begin{array}{l}\text { ONH } \\
\text { RNFL }\end{array}$ & $\begin{array}{l}\text { Rim area } \\
\text { RNFL average thickness }\end{array}$ & $\begin{array}{l}0.87 \\
0.96\end{array}$ \\
\hline Kotowski $2012^{10}$ & $\begin{array}{l}\text { Glaucoma } \\
\text { Glaucoma suspect } \\
\text { Healthy }\end{array}$ & $\begin{array}{l}63 \\
49 \\
51\end{array}$ & $\begin{array}{l}-2.21 \\
-0.32 \\
-0.18\end{array}$ & Cirrus SD-OCT & $\begin{array}{l}\text { Macular } \\
\text { RNFL }\end{array}$ & $\begin{array}{l}\text { GCC average } \\
\text { GCIPL average } \\
\text { RNFL average thickness }\end{array}$ & $\begin{array}{l}0.90 \\
0.90 \\
0.91\end{array}$ \\
\hline Mwanza $2012^{11}$ & $\begin{array}{l}\text { Glaucoma } \\
\text { Healthy }\end{array}$ & $\begin{array}{l}58 \\
99\end{array}$ & $\begin{array}{c}-3.2 \\
0.08\end{array}$ & Cirrus SD-OCT & $\begin{array}{l}\text { Macular } \\
\text { ONH } \\
\text { RNFL }\end{array}$ & $\begin{array}{l}\text { GCIPL minimum } \\
\text { GCIPL average } \\
\text { Vertical cup to disc } \\
\text { ratio } \\
\text { Cup to disc ratio } \\
\text { Rim area } \\
\text { RNFL average thickness }\end{array}$ & $\begin{array}{l}0.96 \\
0.94 \\
0.96 \\
0.93 \\
0.91 \\
0.94\end{array}$ \\
\hline Jeoung $2013^{12}$ & $\begin{array}{l}\text { Glaucoma } \\
\text { Mild } \\
\text { Moderate/severe } \\
\text { Healthy }\end{array}$ & $\begin{array}{l}164 \\
142 \\
119\end{array}$ & $\begin{array}{r}-2.68 \\
-12.41 \\
-0.22\end{array}$ & Cirrus SD-OCT & $\begin{array}{l}\text { Macular } \\
\text { ONH } \\
\text { RNFL }\end{array}$ & $\begin{array}{l}\text { GCIPL minimum } \\
\text { GCIPL average } \\
\text { Rim area } \\
\text { Cup to disc ratio } \\
\text { RNFL average thickness }\end{array}$ & 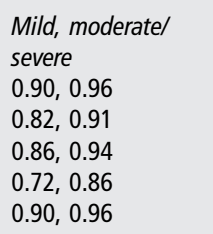 \\
\hline Takayama $2012^{13}$ & $\begin{array}{l}\text { Glaucoma } \\
\text { Early } \\
\text { Advanced } \\
\text { Healthy }\end{array}$ & $\begin{array}{l}38 \\
20 \\
48\end{array}$ & $\begin{array}{c}-2.33 \\
-14.2 \\
-0.07\end{array}$ & Cirrus SD-OCT & $\begin{array}{l}\text { Macular } \\
\text { RFNL }\end{array}$ & $\begin{array}{l}\text { GCIPL minimum } \\
\text { GCIPL average } \\
\text { RNFL average thickness }\end{array}$ & $\begin{array}{l}\text { All, early, advanced } \\
0.94,0.90,0.99 \\
0.87,0.82,0.96 \\
0.92,0.89,0.96\end{array}$ \\
\hline Lisboa $2013^{14}$ & $\begin{array}{l}\text { Preperimetric } \\
\text { glaucoma } \\
\text { Healthy }\end{array}$ & $\begin{array}{l}48 \\
94\end{array}$ & $\begin{array}{r}-0.81 \\
0.02\end{array}$ & $\begin{array}{l}\text { RTVue } \\
\text { SD-OCT }\end{array}$ & $\begin{array}{l}\text { Macular } \\
\text { ONH } \\
\text { RNFL }\end{array}$ & $\begin{array}{l}\text { GCC average } \\
\text { Vertical cup to disc } \\
\text { ratio } \\
\text { Rim area } \\
\text { RNFL average thickness }\end{array}$ & $\begin{array}{l}0.79 \\
0.74 \\
0.72 \\
0.89\end{array}$ \\
\hline
\end{tabular}

AUC, area under receiver operating characteristics curve; GCC, ganglion cell complex; GCIPL, ganglion cell inner plexiform layer; MD, mean deviation; ONH, optic nerve head; RNFL, retinal nerve fibre layer; SD-OCT, spectral domain-optical coherence tomography.

results of these two studies may be attributed to difference in glaucoma severity within the study samples. However, both studies reported similar diagnostic capability with rim area and average RNFL thickness in advanced glaucoma. The role of SD-OCT ONH analysis in glaucoma diagnosis is yet to be determined.

While total macular thickness (TMT) has been associated with glaucoma, the diagnostic capabilities have been reported to be worse than with RNFL thickness. However, SD-OCT segmentation algorithms have enabled quantification of individual layers in the macular region that are particularly impacted by glaucomatous damage, specifically, macular RNFL (mRNFL), ganglion cell layer with inner plexiform layer (GCIPL) and ganglion cell complex $(\mathrm{GCC}=\mathrm{mRNFL}+\mathrm{GCIPL})$. Recent studies reported similar area under the receiver operating characteristics diagnostic capability of GCIPL that was comparable with $\mathrm{RNFL}^{10}{ }^{11}$ and ONH parameters. ${ }^{11}{ }^{12}$ Furthermore, of the various GCIPL-specific parameters (average, minimum, sectoral), minimum GCIPL has been reported to be the most sensitive for the diagnosis of glaucoma. ${ }^{12} 13$

SD-OCT diagnostic studies have demonstrated that glaucomatous damage results in thinning of RNFL and GCIPL as well as $\mathrm{ONH}$ structural changes that allow for discrimination between glaucoma and healthy eyes. However, in most of these studies, the diagnostic accuracy may not translate when used in clinical practice for early stage glaucoma detection because the discrimination studies are usually based on differentiating healthy eyes from eyes with established glaucomatous visual field (VF) loss. A recent SD-OCT study compared the diagnostic ability of RNFL, ONH and macular parameters for diagnosing preperimetric glaucoma in an observational cohort with 13 years of follow-up. ${ }^{14}$ The investigators demonstrated that RNFL parameters performed significantly better than $\mathrm{ONH}$ and macular parameters for detecting preperimetric glaucomatous damage. It is plausible that a combination of parameters from the various scanned regions can improve diagnostic performance; however, this has yet to be evaluated.

Myopia is a risk factor for glaucoma and a confounder that complicates diagnosis because it presents with structural changes that can progressively lead to glaucomatous-appearing VF defects. ${ }^{15}$ Myopic refractive error and longer axial lengths impact RNFL and macular thickness measurements due to the optical projection artefact of the scanning area. It has been demonstrated that non-glaucomatous myopic eyes tend to have thinner RNFL and macular parameters that are falsely classified as abnormal by OCT. ${ }^{16}$ Recent SD-OCT diagnostic performance studies on glaucomatous eyes with high myopia have demonstrated that RNFL and macular thickness parameters have similar ability to detect glaucoma. ${ }^{17} 18$

The quality of reporting of diagnostic studies for glaucoma using OCT has been demonstrated overall to be suboptimal with only $26.7 \%$ of selected papers reporting more than half of the standards for the reporting of diagnostic accuracy studies (STARD) criteria items. ${ }^{19}$ Using the same criteria, $100 \%$ of the 
selected diagnostic studies in this review reported more than half of the STARD items (mean 71.4\%; range 54\%-92\%).

In summary, the literature to date suggests that RNFL thickness remains the most diagnostically accurate parameter for detecting glaucoma. Though there have been some conflicting reports, several studies suggest that the diagnostic performance of segmented macular and $\mathrm{ONH}$ parameters are comparable with RNFL parameters. Furthermore, there is a reported difference in RNFL thickness measurement between different SD-OCT devices attributed to variation in optical properties and segmentation algorithms, and therefore the measurements are not inter-changeable between devices. ${ }^{20}$ However, despite these variations, the devices have demonstrated similar diagnostic capabilities. ${ }^{21}$

\section{GLAUCOMA SCREENING}

Individuals with glaucoma are usually asymptomatic until late in the disease processes and it is possible to either slow or prevent the progression of vision loss if detected early by adequate treatment. Therefore, a glaucoma screening tool for the general population is desirable. Population-based glaucoma screening is currently not cost-effective but it may be more beneficial and cost-effective in a targeted high-risk population such as older African Americans and Hispanics or those with a family history of glaucoma. Screening for glaucoma in a community-based high-risk population with TD-OCT resulted in moderate sensitivity and high specificity for definitive glaucoma suggesting that the device does not have adequate sensitivity to be used alone but may have utility in excluding subjects from further evaluation. $^{22}$ However, SD-OCT has been reported to have higher sensitivity than TD-OCT in glaucoma screening and may have potential for early detection in a high-risk population. ${ }^{7}$ As of this writing, the use of SD-OCT for glaucoma screening in high-risk populations has not been reported. The United States Agency for Healthcare Research and Quality evaluated the evidence from the primary studies that investigated the diagnostic performance of OCT and reported that all the studies had appreciable heterogeneity and were at risk of investigating subjects that did not reflect the general or the clinically relevant population (spectrum bias). ${ }^{6}$ In summary, OCT currently lacks the necessary diagnostic performance for general population glaucoma screening.

\section{GLAUCOMA PROGRESSION}

Once glaucoma is diagnosed, a sensitive method for detection of progression is essential because appropriately intensifying treatment can slow RGC loss and preserve vision. The detection of glaucoma progression with OCT remains a challenge because when assessing structural changes over time, it is difficult to discriminate between glaucomatous structural damage and measurement variability or age-related structural loss. A prospective study assessing age-related loss enrolled 100 healthy subjects for crosssectional evaluation and then randomly selected 35 subjects for 30 months of longitudinal evaluation. ${ }^{23}$ Cross-sectional analysis of healthy subjects demonstrated a significant negative correlation between age and average RNFL thickness of $-0.33 \mu \mathrm{m} /$ year while the longitudinal analysis reported a $-0.52 \mu \mathrm{m} / \mathrm{year}$ rate of age-related loss of RNFL. Furthermore, the same study reported that age-related structural loss varies as a function of baseline RNFL where a higher baseline thickness is subject to higher rates of decline.

Table 2 Summary of selected longitudinal studies of glaucoma progression detection

\begin{tabular}{|c|c|c|c|c|c|c|c|}
\hline $\begin{array}{l}\text { Study, year } \\
\text { (reference) }\end{array}$ & $\begin{array}{l}\text { Duration } \\
\text { (years) }\end{array}$ & Subjects & $\begin{array}{l}\text { Number } \\
\text { of eyes }\end{array}$ & Device & $\begin{array}{l}\text { Progression } \\
\text { standard }\end{array}$ & $\begin{array}{l}\text { Progression } \\
\text { parameters }\end{array}$ & Summary \\
\hline $\begin{array}{l}\text { Wollstein } \\
2005^{25}\end{array}$ & 4.7 & $\begin{array}{l}\text { Glaucoma } \\
\text { Glaucoma } \\
\text { Suspect }\end{array}$ & $\begin{array}{r}55 \\
9\end{array}$ & $\begin{array}{l}\text { Prototype } \\
\text { TD-OCT }\end{array}$ & Visual field & RNFL & $\begin{array}{l}\text { Greater likelihood of progression as measured by } \\
\text { OCT compared with visual field }\end{array}$ \\
\hline Wessel $2013^{26}$ & 3 & $\begin{array}{l}\text { Glaucoma } \\
\text { Healthy }\end{array}$ & $\begin{array}{l}38 \\
24\end{array}$ & $\begin{array}{l}\text { Spectralis } \\
\text { SD-OCT }\end{array}$ & Optic disc photos & RNFL & $\begin{array}{l}\text { Significant difference in rate of structural change } \\
\text { between glaucoma progressors }(2.12 \mu \mathrm{m} / \text { year }) \text { and } \\
\text { non-progressors }(-1.18 \mu \mathrm{m} / \text { year })\end{array}$ \\
\hline $\begin{array}{l}\text { Naghizadeh } \\
2013^{27}\end{array}$ & 2 & $\begin{array}{l}\text { Glaucoma } \\
\text { Healthy }\end{array}$ & $\begin{array}{l}51 \\
17\end{array}$ & $\begin{array}{l}\text { RTVue } \\
\text { SD-OCT }\end{array}$ & Visual field & $\begin{array}{l}\text { RNFL } \\
\text { ONH } \\
\text { macular }\end{array}$ & $\begin{array}{l}\text { Glaucoma eyes had non-significant rates of } \\
\text { structural change in RNFL ( }-0.33 \mu \mathrm{m} / \mathrm{year}) \text {, cup area } \\
\left(0.03 \mathrm{~mm}^{2} / \text { year }\right) \text {, rim area }\left(-0.03 \mathrm{~mm}^{2} / \text { year) and }\right. \\
\text { GCC }(-0.19 \mu \mathrm{m} / \text { year). Only GCC global ( } 3.8 \% / y e a r) \\
\text { and focal }(1.5 \% / \text { year) loss volumes had significant } \\
\text { rates of structural change compared with healthy } \\
\text { eyes }\end{array}$ \\
\hline $\mathrm{Na} 2012^{28}$ & 2.1 & $\begin{array}{l}\text { Glaucoma } \\
\text { Healthy }\end{array}$ & $\begin{array}{r}141 \\
61\end{array}$ & $\begin{array}{l}\text { Cirrus } \\
\text { SD-OCT }\end{array}$ & $\begin{array}{l}\text { Optic disc photos, } \\
\text { red-free RNFL photos }\end{array}$ & $\begin{array}{l}\text { RNFL } \\
\text { macular }\end{array}$ & $\begin{array}{l}\text { No significant difference in sensitivity to detect } \\
\text { glaucoma progression among RNFL (5\%), TMT } \\
(14 \%) \text { and GCIPL }(8 \%)\end{array}$ \\
\hline Sung $2012^{29}$ & 2.2 & Glaucoma & 98 & $\begin{array}{l}\text { Cirrus } \\
\text { SD-OCT }\end{array}$ & $\begin{array}{l}\text { Optic disc photos, } \\
\text { red-free RNFL photos, } \\
\text { visual field }\end{array}$ & $\begin{array}{l}\text { RNFL } \\
\text { macular }\end{array}$ & $\begin{array}{l}\text { By photographs, glaucoma progressors had } \\
\text { structural rates of RNFL change of }-1.19 \mu \mathrm{m} / \mathrm{year} \\
\text { and macular thickness }-4.74 \mu \mathrm{m} / \text { year. By visual } \\
\text { field index, glaucoma progressors had structural } \\
\text { rates of RNFL change of }-2.08 \mu \mathrm{m} / \mathrm{year} \text { and macular } \\
\text { thickness }-5.12 \mu \mathrm{m} / \mathrm{year} \text {. Only macular rates of } \\
\text { change were significantly different from glaucoma } \\
\text { non-progressors }\end{array}$ \\
\hline Na $2013^{30}$ & 2.2 & Glaucoma & 279 & $\begin{array}{l}\text { Cirrus } \\
\text { SD-OCT }\end{array}$ & $\begin{array}{l}\text { Optic disc photos, } \\
\text { red-free RNFL photos, } \\
\text { visual field }\end{array}$ & $\begin{array}{l}\text { RNFL } \\
\text { ONH } \\
\text { macular }\end{array}$ & $\begin{array}{l}\text { Glaucoma progressors had significantly different } \\
\text { rates of structural change in RNFL ( }-1.26 \mu \mathrm{m} / \text { year), } \\
\text { rim area }\left(-0.02 \mathrm{~mm}^{2} / \text { year), average cup to disc ratio }\right. \\
\text { ( } 0.004 / \text { year) and macular cube volume }(-0.07 \mu \mathrm{m} / \\
\text { year) compared with glaucoma non-progressors }\end{array}$ \\
\hline
\end{tabular}


SD-OCT has been reported to be more sensitive than TD-OCT in detecting RNFL changes in glaucoma progression. $^{24}$ SD-OCT glaucoma progression algorithms measure changes based on either event-based or trend-based analysis. Event-based analysis detects progression when a follow-up measurement exceeds a pre-established threshold for change from baseline. This analysis identifies a gradual change over time that eventually crosses a threshold or an acute event that exceeds a threshold. The limitation of this approach is the susceptibility to the effect of outliers that can be inappropriately labelled as progression. Trend-based analysis detects progression by evaluating the slope of measured parameter over time. Trend analysis is less sensitive to measurement variability and identifies a rate of progression that may be extrapolated for time-to-event predictions. The limitation of this approach is the requirement for a large number of tests before the analysis can be considered as reliable. Furthermore, trend analysis has an a priori assumption of a linear rate of structural loss, which might not be applicable for all eyes.

Table 2 summarises selected longitudinal studies of glaucoma progression. The first study to show the potential of OCT in detecting glaucoma progression used an event-based approach to evaluate TD-OCT RNFL thickness measurements over time and reported a mean loss of average RNFL thickness of $11.7 \mu \mathrm{m}$ over 4.7 years in glaucoma subjects. ${ }^{25}$ In a longitudinal SD-OCT study of glaucoma and healthy eyes followed for 3 years, the investigators reported a significantly greater rate of RNFL loss in glaucomatous optic disc progressors compared with non-progressors. ${ }^{26}$ A 2-year study of perimetric glaucoma and healthy eyes with SD-OCT scans demonstrated superior detection of early glaucomatous progression with measurement of GCC global loss volume and focal loss volume compared with ONH, RNFL thickness and average GCC parameters. $^{27}$

A longitudinal study of glaucoma and healthy eyes reported that compared with RNFL, TMT and GCIPL showed similar levels of sensitivity in glaucoma progression detection. ${ }^{28}$ A longitudinal study of eyes with advanced glaucoma, as determined by VF, demonstrated that the rate of average macular thickness loss was significantly greater in the progressed group versus the stable and undetermined groups. ${ }^{29}$ Furthermore, the rate of average RNFL thickness loss was similar among the groups, suggesting that macular thickness assessment may be used to detect progression in advanced glaucoma. Another longitudinal study of 279 glaucoma eyes reported that RNFL thickness, macular and $\mathrm{ONH}$ parameters decreased significantly faster in progressors versus non-progressors as determined by optic disc, RNFL and VF assessment. ${ }^{30}$ These studies indicate that the macular region is appropriate for detection of glaucoma progression; however, they are all limited by short follow-up periods that did not last more than 2 years.

Myopia confounds the evaluation of glaucoma progression because it is difficult to discern the difference between progression due primarily to myopia or glaucoma. Since it is not possible to distinguish glaucomatous from non-glaucomatous changes based on a single examination, it is appropriate to conservatively follow highly myopic patients with suspected glaucoma after establishing baseline structural and functional parameters. ${ }^{15}$ As of this manuscript, no study has attempted to evaluate the effect of myopia on detection of glaucoma progression.

In summary, the literature to date suggests that RNFL thickness is a dominant parameter in detection of glaucoma progression. However, macular parameters might provide a useful alternative for glaucoma progression assessment. The results of all available studies need to be cautiously evaluated in light of the relatively short duration of follow-up in the context of the typically slowly progressing glaucoma.

\section{CONCLUSIONS}

SD-OCT is a valuable clinical tool for glaucoma diagnosis and detection of progression. RNFL parameters have been demonstrated to provide accurate information for disease diagnosis and sensitive method for disease progression. Initial studies evaluating macular and $\mathrm{ONH}$ parameters show encouraging results.

Contributors IIB: drafting the article. GW: revising the article critically for important intellectual content and final approval of the version to be published. JSS: final approval of the version to be published.

Funding Supported in part by National Institutes of Health contracts $\mathrm{NIH}$ R01-EY013178, P30-EY008098 (Bethesda, Maryland, USA); The Eye and Ear Foundation (Pittsburgh, Pennsylvania, USA); and Research to Prevent Blindness (New York, New York, USA).

Competing interests Dr Wollstein is a consultant for Allergan. Dr. Schuman receives royalties for intellectual property licensed by Massachusetts Institute of Technology to Zeiss.

Provenance and peer review Not commissioned; externally peer reviewed.

Open Access This is an Open Access article distributed in accordance with the Creative Commons Attribution Non Commercial (CC BY-NC 3.0) license, which permits others to distribute, remix, adapt, build upon this work non-commercially, and license their derivative works on different terms, provided the original work is properly cited and the use is non-commercial. See: http://creativecommons.org/ licenses/by-nc/3.0/

\section{REFERENCES}

1 Huang D, Swanson EA, Lin CP, et al. Optical coherence tomography. Science 1991;254:1178-81.

2 Hee MR, Izatt JA, Swanson EA, et al. Optical coherence tomography of the human retina. Arch Ophthalmol 1995;113:325-32.

3 Wong JJ, Chen TC, Shen LQ, et al. Macular imaging for glaucoma using spectral-domain optical coherence tomography: a review. Semin Ophthalmol 2012:27:160-6.

4 Mansouri K, Leite MT, Medeiros FA, et al. Assessment of rates of structural change in glaucoma using imaging technologies. Eye 2011;25:269-77.

5 Sung KR, Wollstein G, Kim NR, et al. Macular assessment using optical coherence tomography for glaucoma diagnosis. Br J Ophthalmol 2012;96:1452-5.

6 Ervin AM, Boland MV, Myrowitz EH, et al. Screening for glaucoma: comparative effectiveness. Comparative effectiveness reviews. Rockville, MD: Agency for Healthcare Research and Quality, 2012.

7 Bengtsson B, Andersson S, Heijl A. Performance of time-domain and spectral-domain Optical Coherence Tomography for glaucoma screening. Acta Ophthalmol 2010;90:310-5

8 Mwanza JC, Oakley JD, Budenz DL, et al. Ability of cirrus HD-OCT optic nerve head parameters to discriminate normal from glaucomatous eyes. Ophthalmology 2011;118:241-8

9 Sung KR, Na JH, Lee Y. Glaucoma diagnostic capabilities of optic nerve head parameters as determined by Cirrus HD optical coherence tomography. J Glaucoma 2012;21:498-504.

10 Kotowski J, Folio LS, Wollstein G, et al. Glaucoma discrimination of segmented cirrus spectral domain optical coherence tomography (SD-OCT) macular scans. $\mathrm{Br} J$ Ophthalmol 2012;96:1420-5.

11 Mwanza JC, Durbin MK, Budenz DL, et al. Glaucoma diagnostic accuracy of ganglion cell-inner plexiform layer thickness: comparison with nerve fiber layer and optic nerve head. Ophthalmology 2012;119:1151-8.

12 Jeoung JW, Choi YJ, Park KH, et al. Macular ganglion cell imaging study: glaucoma diagnostic accuracy of spectral-domain optical coherence tomography. Invest Ophthalmol Vis Sci 2013;54:4422-9.

13 Takayama K, Hangai M, Durbin M, et al. A novel method to detect local ganglion cell loss in early glaucoma using spectral-domain optical coherence tomography. Invest Ophthalmo/Vis Sci 2012;53:6904-13.

14 Lisboa R, Paranhos A Jr, Weinreb RN, et al. Comparison of different spectral domain OCT scanning protocols for diagnosing preperimetric glaucoma. Invest Ophthalmol Vis Sci 2013;54:3417-25.

15 Chang RT, Singh K. Myopia and glaucoma: diagnostic and therapeutic challenges Curr Opin Ophthal 2013;24:96-101.

16 Mwanza JC, Sayyad FE, Aref AA, et al. Rates of abnormal retinal nerve fiber layer and ganglion cell layer OCT scans in healthy myopic eyes: cirrus versus RTVue. Ophthalmic Surg Lasers Imaging 2012;43(6 Suppl):S67-74. 
17 Choi YJ, Jeoung JW, Park KH, et al. Glaucoma detection ability of ganglion cell-inner plexiform layer thickness by spectral-domain optical coherence tomography in high myopia. Invest Ophthalmol Vis Sci 2013:54:2296-304.

18 Akashi A, Kanamori A, Nakamura $M$, et al. The ability of macular parameters and circumpapillary retinal nerve fiber layer by three SD-OCT instruments to diagnose highly myopic glaucoma. Invest Ophthal Vis Sci 2013;54:6025-32.

19 Johnson ZK, Siddiqui MA, Azuara-Blanco A. The quality of reporting of diagnostic accuracy studies of optical coherence tomography in glaucoma. Ophthalmology 2007;114:1607-12.

20 Pierro L, Gagliardi M, luliano L, et al. Retinal nerve fiber layer thickness reproducibility using seven different OCT instruments. Invest Ophthal Vis Sci 2012;53:5912-20.

21 Akashi A, Kanamori A, Nakamura M, et al. Comparative Assessment for the Ability of Cirrus, RTVue, and 3D-OCT to Diagnose Glaucoma. Invest Ophthal Vis SCi 2013;54:4478-84.

22 Li G, Fansi AK, Boivin JF, et al. Screening for glaucoma in high-risk populations using optical coherence tomography. Ophthalmology 2010;117:453-61.

23 Leung $C K$, Yu M, Weinreb RN, et al. Retinal nerve fiber layer imaging with spectral-domain optical coherence tomography: a prospective analysis of age-related loss. Ophthalmology 2012;119:731-7.
24 Leung CK, Chiu V, Weinreb RN, et al. Evaluation of retinal nerve fiber layer progression in glaucoma: a comparison between spectral-domain and time-domain optical coherence tomography. Ophthalmology 2011;118:1558-62.

25 Wollstein G, Schuman JS, Price LL, et al. Optical coherence tomography longitudinal evaluation of retinal nerve fiber layer thickness in glaucoma. Arch Ophthalmol 2005;123:464-70.

26 Wessel JM, Horn FK, Tornow RP, et al. Longitudinal analysis of progression in glaucoma using spectral-domain optical coherence tomography. Invest Ophthalmol Vis Sci 2013;54:3613-20.

27 Naghizadeh F, Garas A, Vargha P, et al. Detection of early glaucomatous progression with different parameters of the RTVue optical coherence tomograph. J Glaucoma. In press.

$28 \mathrm{Na} \mathrm{JH}$, Sung KR, Baek S, et al. Detection of glaucoma progression by assessment of segmented macular thickness data obtained using spectral domain optical coherence tomography. Invest Ophthalmol Vis Sci 2012;53:3817-26.

29 Sung KR, Sun JH, Na JH, et al. Progression detection capability of macular thickness in advanced glaucomatous eyes. Ophthalmology 2012;119:308-13.

$30 \mathrm{Na} J \mathrm{H}$, Sung KR, Lee JR, et al. Detection of glaucomatous progression by spectral-domain optical coherence tomography. Ophthalmology 2013; 120:1388-95. 